\title{
Zubrod Performance Status 3
}

National Cancer Institute

\section{Source}

National Cancer Institute. Zubrod Performance Status 3. NCI Thesaurus. Code C17847.

Capable of only limited self-care, confined to bed or chair more than 50\% of waking hours. (Eastern Cooperative Oncology Group) 